\title{
The associations between G972R polymorphism of the IRS-1 gene, insulin resistance, salt sensitivity and non-dipper hypertension
}

\author{
Joanna Dziwura ${ }^{1}$, Agnieszka Bińczak-Kuleta ${ }^{2}$, Tomasz Miazgowski ${ }^{1}$, Joanna Ziemak ${ }^{1}$ and Krystyna Widecka ${ }^{1}$
}

The aim of this study was to assess the association between G972R polymorphism of the insulin receptor substrate-1 (IRS-1) gene and the circadian variation in blood pressure, insulin sensitivity and salt sensitivity in subjects with uncomplicated, never-treated essential hypertension receiving low-, normal- and high-salt diets. The study was performed on 115 subjects aged $27.48 \pm 5.1$ years with never-treated, uncomplicated hypertension. In the 7-day consecutive period of time, subjects received a normal-, low- and high-salt diet. At the end of each dietary regimen, the following parameters were recorded: 24-h blood pressure monitoring, lipid profile, insulin level, glucose level, aldosterone level and plasma renin activity. Insulin resistance was evaluated by the homeostasis model assessment (HOMA). In comparison with Gly/Gly carriers, subjects with the G972R polymorphism had higher concentrations of total and LDL cholesterol and triglycerides and HOMA but lower HDL cholesterol. On a high-salt diet, patients with the G972R polymorphism had an increased risk for insulin resistance (odds ratio (OR) $=11.42$, 95\% confidence interval $(\mathrm{Cl}) 7.68-28.44)$, salt sensitivity ( $\mathrm{OR}=5.38,95 \% \mathrm{Cl} 1.14-25.34)$ and non-dipper hypertension $(\mathrm{OR}=3.6,95 \% \mathrm{Cl} 1.07-12.09)$. Regardless of the dietary salt intake, blood pressure values were similar between G972R and Gly/Gly carriers. In conclusion, the results of our study suggest that the G972R polymorphism of the IRS-1 gene is associated with insulin resistance, salt sensitivity and non-dipper hypertension.

Hypertension Research (2011) 34, 1082-1086; doi:10.1038/hr.2011.80; published online 16 June 2011

Keywords: insulin resistance; non-dippers; salt sensitivity

\section{INTRODUCTION}

Hypertension is rarely an isolated condition and is commonly associated with an abnormal glucose tolerance, abnormal lipid profile and increased risk for cardiovascular diseases. Insulin resistance is generally recognized as a core factor in the pathogenesis of type 2 diabetes as well as hypertension and atherosclerosis.

Insulin resistance and hyperinsulinemia affect $\sim 50 \%$ of patients with hypertension. ${ }^{1}$ Hyperinsulinemia increases renal sodium reabsorption, leading to an increase in the circulating blood volume and the development of salt-sensitive hypertension. ${ }^{2-5}$ In turn, the salt-sensitive hypertension, defined as the variation of blood pressure in response to different dietary salt intakes, is recognized as an unfavorable feature of the disease because it may predispose patients to organ complications induced by elevated blood pressure. ${ }^{6-8}$

It has been documented that increased genetic predisposition to hypertension is often accompanied by an increased predisposition to insulin resistance. ${ }^{9,10}$ In the search for susceptibility loci predisposing to insulin resistance, earlier studies have identified a common coding variant of the substitution of a glycine residue for arginine at position 972 (G972R) of the insulin receptor substrate-1 gene (IRS-1) as possibly being associated with impaired insulin action, resulting in the development of type 2 diabetes and obesity. ${ }^{11-18}$ However, the role of the G972R polymorphism in uncomplicated hypertension has not been elucidated. It has been suggested that, in human endothelial cells, the G972R polymorphism may reduce insulin's ability to activate the signaling pathway that regulates nitric oxide activity and, therefore, contribute to the development of endothelial dysfunction and cardiovascular disease. ${ }^{19,20}$

There have been no earlier reports testing for associations between the G972R variant of the IRS-1 gene and the salt sensitivity of hypertension. Thus, the purpose of this study was to assess the impact of this polymorphism on the circadian variation in blood pressure, insulin sensitivity and salt sensitivity in patients with uncomplicated, never-treated essential hypertension receiving low-, normal- or high-salt diets.

\section{METHODS}

Study population

The study was performed on 115 unrelated Caucasian patients with hypertension aged $27.5 \pm 5.1$ years. The inclusion criteria during this study were as follows: age below 35 years and uncomplicated, never-treated, essential hypertension grade 1 or 2 according to the European Society of Hypertension

${ }^{1}$ Department of Hypertension and Internal Diseases, Pomeranian Medical University, Szczecin, Poland and 2Department of Clinical and Molecular Biochemistry, Pomeranian Medical University, Szczecin, Poland

Correspondence: Dr T Miazgowski, Department of Hypertension and Internal Diseases, Pomeranian Medical University, ul. Unii Lubelskiej 1, 71-252 Szczecin, Poland. E-mail: miazgowski@interia.pl

Received 24 January 2011; revised 12 March 2011; accepted 6 April 2011; published online 16 June 2011 
(ESH) and the European Society of Cardiology (ESC) classifications. ${ }^{21}$ We included only those subjects who did not have any medical conditions requiring treatment on the first visit. Exclusion criteria included: obesity (body mass index $\geqslant 30 \mathrm{~kg} \mathrm{~m}^{-2}$ ), history of chronic renal disease, chronic heart or hepatic failure, diabetes mellitus, cardiac arrhythmia and edema. None of the patients received any concomitant treatments within the three weeks preceding this study.

Hypertension was diagnosed during three visits performed on different days. Blood pressure was measured in sitting position between 0800 and 0900 hours by a mercury sphygmomanometer 3 times in 2-min intervals, and a mean value of these measurements was assumed in further analyses, according to the ESH/ESC guidelines. ${ }^{21}$ Using imaging techniques as well as biochemical and hormonal assessment, all patients were examined to rule out secondary hypertension.

\section{Methods}

Patients were hospitalized in the Department of Hypertension and Internal Medicine, Pomeranian Medical University, Szczecin, Poland for twenty-one consecutive days. During this time, patients received a diet containing normal (100-120 mmol per day), low (10-20 mmol per day) and high (220-240 mmol per day) salt loads for seven-day intervals. Only those subjects who were in salt balance, as evaluated by a 24 -h urinary sodium excretion, during all three diet regimens were included in the analysis. Regardless of the salt intake, dietary potassium intake was stable $(40-50 \mathrm{mmol}$ per day) throughout the whole study period. Meals were prepared by a trained hospital dietician. The dietary compliance was monitored by a daily sodium urinary excretion.

On the seventh day of the normal-salt diet, after an overnight fast, blood samples were collected in a supine position to record the serum sodium, potassium, creatinine, glucose, insulin and cholesterol (total and its LDL and HDL fractions) levels, plasma renin activity (PRA) and aldosterone (ALDO). Additionally, blood samples were collected for DNA isolation.

After consuming the normal-salt diet, patients received the low-salt diet followed by the high-salt diet. On the sixth and seventh day of each of the dietary regimens, 24-h urine samples were collected for urinary sodium and potassium excretion. On the 6th day of each of the dietary regimens, at 0900 hours, a 24-h blood pressure monitoring (ABPM) protocol was performed using a Spacelabs 90207 monitor (Spacelabs Healthcare; Issaquah, WA, USA). Blood pressure was measured every $20 \mathrm{~min}$ during the daytime (0600-2200) and every $30 \mathrm{~min}$ at nighttime (2200-0600). The following parameters were recorded: 24-h mean (MAP), daytime mean (DMAP) and nighttime mean (NMAP) blood pressures. A patient was defined as having dipper hypertension if his or her declines in blood pressure at night were at least $10 \%$ of the daytime values; a patient was defined as having non-dipper hypertension if his or her declines in blood pressure at night were below $10 \%{ }^{22}$

On the seventh day of the low- and high-salt diets, after an overnight fast, blood samples were drawn in a supine position to record the serum glucose and insulin levels, ALDO and PRA. Salt sensitivity of hypertension was diagnosed when MAP increased $>10 \mathrm{~mm} \mathrm{Hg}$ after switching from a low- to high-salt diet given for at least 5 days. ${ }^{23,24}$

Insulin resistance was evaluated by the homeostasis model assessment (HOMA) index, calculated as blood glucose $\left(\mathrm{mmoll}^{-1}\right) \times$ insulin concentration $\left(\mu \mathrm{IU} \mathrm{ml}^{-1}\right) / 22.5 .^{25,26}$

Body mass index was calculated as weight (kilograms) divided by height (meters) squared.

\section{Assays}

Insulin was assessed by an ELISA (DPC Biermann GmbH, Bad Nauheim, Germany), serum glucose by an enzymatic method (Cobas Integra; Roche Diagnostica GmbH, Mannheim, Germany) and lipid profile by an enzymatic colorimetric method (Cobas Integra). Blood samples for PRA and ALDO evaluation were centrifuged at $3900 \mathrm{~g}$ for $10 \mathrm{~min}$ at $4{ }^{\circ} \mathrm{C}$, and the specimens were stored at $-70^{\circ} \mathrm{C}$ for subsequent batch analysis by RIA (Serono, Milan, Italy). The results of ALDO and PRA were expressed as the ALDO/PRA ratio. ${ }^{27}$ Genomic DNA was extracted from peripheral EDTA-treated blood cells using the QIAamp DNA Mini Kit (QIAGEN Genomics, Bothell, WA, USA). The
Arg972 substitution was detected by digestion of polymerase chain reaction products with restriction enzymes, as described previously. ${ }^{28}$

The study protocol was approved by the institutional ethics committee, and informed written consent was obtained from each subject in accordance with principles of the Declaration of Helsinki.

\section{Statistical analysis}

The distribution of continuous variables was tested for normality by the Shapiro-Wilk test. Parametric data are reported as mean \pm s.d. Two-way analysis of variance (ANOVA) for correlated errors was used to determine the associations between the G972R polymorphism of the IRS-1 gene and insulin resistance, salt sensitivity and non-dipper hypertension on normal-, low- and high-salt diets. Unpaired $t$-tests were used in addition to ANOVA for comparisons between groups. Categorical variables were compared using the $\chi^{2}$ test. Univariate logistic regression models adjusted for gender and BMI were used to test for relationships between salt sensitivity, insulin resistance, nondipper phenotype and the IRS-1 G972R polymorphism. The results of the analysis were expressed as odds ratios (ORs) and 95\% confidence intervals (CIs). All comparisons were performed using the statistical package Statistica (Statsoft, Tulsa, OK, USA).

\section{RESULTS}

Genotype frequencies were Gly/Gly 86\%, Gly/Arg 14\% and Arg/Arg $0 \%$ that was in Hardy-Weinberg equilibrium. Baseline clinical characteristics of Gly/Gly patients (GG) and heterozygous carriers for the G972R IRS-1 variant (GA) receiving a normal-salt diet are given in Table 1. In comparison with the GG genotype, patients with the GA genotype had higher concentrations of total and LDL

Table 1 Baseline characteristics of the study population receiving normal-salt diet in relation to the IRS-1 polymorphism

\begin{tabular}{|c|c|c|c|}
\hline & $\begin{array}{c}\text { Gly/Arg } \\
\text { patients } \\
(\mathrm{n}=16)\end{array}$ & $\begin{array}{c}\text { Gly/Gly } \\
\text { patients } \\
(\mathrm{n}=99)\end{array}$ & $P$ \\
\hline Age (years) & $25.6 \pm 4.7$ & $27.8 \pm 5.2$ & 0.15 \\
\hline Gender (males/females) & $6 / 10$ & $54 / 45$ & 0.29 \\
\hline Smokers $(n)$ & $3(19 \%)$ & $18(18 \%)$ & 0.91 \\
\hline Body mass index $\left(\mathrm{kg} \mathrm{m}^{-2}\right)$ & $24.8 \pm 1.1$ & $24.5 \pm 1.9$ & 0.44 \\
\hline Systolic blood pressure $(\mathrm{mm} \mathrm{Hg})$ & $150.3 \pm 6.7$ & $151.1 \pm 7.2$ & 0.23 \\
\hline Diastolic blood pressure $(\mathrm{mm} \mathrm{Hg})$ & $97.8 \pm 4.1$ & $97.4 \pm 3.1$ & 0.92 \\
\hline Mean blood pressure (mm Hg) & $115.3 \pm 4.0$ & $114.9 \pm 3.8$ & 0.36 \\
\hline Serum glucose $\left(\mathrm{mg} \mathrm{dl}^{-1}\right)$ & $89.8 \pm 4.7$ & $88.9 \pm 6.8$ & 0.21 \\
\hline Serum insulin $\left(\mu \mathrm{IU} \mathrm{ml^{-1 }}\right)$ & $13.5 \pm 5.9$ & $7.1 \pm 3.5$ & 0.003 \\
\hline HOMA & $3.0 \pm 1.3$ & $1.6 \pm 0.8$ & 0.004 \\
\hline Total cholesterol (mg dl-1) & $218.3 \pm 36.0$ & $196.4 \pm 26.9$ & 0.009 \\
\hline HDL cholesterol (mg dl ${ }^{-1}$ ) & $37.7 \pm 10.8$ & $49.9 \pm 11.3$ & 0.004 \\
\hline LDL cholesterol (mg dl ${ }^{-1}$ ) & $150.7 \pm 39.6$ & $124.7 \pm 30.1$ & 0.001 \\
\hline Triglycerides $\left(\mathrm{mg} \mathrm{dl}^{-1}\right)$ & $149.1 \pm 47.1$ & $109.2 \pm 34.8$ & 0.001 \\
\hline Creatinine $\left(\mathrm{mg} \mathrm{dl}^{-1}\right)$ & $0.95 \pm 0.13$ & $0.89 \pm 0.14$ & 0.09 \\
\hline Serum sodium $\left(\mathrm{mmol} \mathrm{I}^{-1}\right)$ & $140.5 \pm 1.8$ & $140.7 \pm 2.3$ & 0.68 \\
\hline Serum potassium (mmol ${ }^{-1}$ ) & $4.3 \pm 0.3$ & $4.4 \pm 0.36$ & 0.81 \\
\hline $\begin{array}{l}\text { Urinary sodium excretion } \\
\text { (mmol per } 24 \mathrm{~h})\end{array}$ & $121.4 \pm 15.1$ & $124.4 \pm 10.9$ & 0.14 \\
\hline $\begin{array}{l}\text { Urinary potassium excretion } \\
\text { (mmol per } 24 \mathrm{~h})\end{array}$ & $39.8 \pm 15.6$ & $42.1 \pm 19.3$ & 0.22 \\
\hline 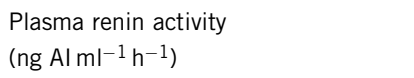 & $2.8 \pm 0.98$ & $2.5 \pm 0.9$ & 0.10 \\
\hline Aldosterone (pg ml-1) & $198.5 \pm 41.8$ & $195.0 \pm 42.0$ & 0.17 \\
\hline Aldosterone/plasma renin activity ratio & $7.9 \pm 3.0$ & $8.9 \pm 3.3$ & 0.11 \\
\hline
\end{tabular}

Abbreviation: HDL, high-density lipoprotein; HOMA, homeostasis model assessment; IRS-1, insulin receptor substrate-1; LDL, low-density lipoprotein. Data are means \pm s.d. 
cholesterol, triglycerides and HOMA index, but lower HDL cholesterol levels.

On the low- and high-salt diets, GA and GG patients had similar values for the 24-h blood pressure recordings, both during the daytime and at night (Table 2). Similarly, PRA and ALDO concentration did not differ between groups. By contrast, fasting insulin levels and insulin resistance, estimated from the HOMA index, were significantly higher in heterozygous carriers of the G972R polymorphism compared with Gly/Gly carriers. These differences were much more pronounced on a high-salt diet.

As expected, when analyzing the impact of low- and high-salt diets on blood pressure, PRA, serum insulin, glucose and ALDO, in both groups a high-salt diet increased 24-h MAP and nighttime blood pressure, but decreased PRA and ALDO. Of note, a nighttime blood pressure fall on the high-salt diet was significantly smaller than on the low-salt diet $(P=0.02)$, but only in GA carriers. Moreover, in heterozygous carriers of the G972R IRS-1 variant, but not in Gly/Gly carriers, a high-salt diet resulted in a significant increase in serum insulin and insulin resistance, although glucose concentrations were still within the normal range.

The frequency distribution of insulin resistance, defined as HOMA values $\geqslant 2.5,{ }^{26}$ non-dipper and salt-sensitive hypertension is shown in Table 3. In comparison with GG carriers, we found higher incidence of salt-sensitive hypertension in GA carriers. Regardless of the dietary salt intake, the frequency of insulin resistance was significantly higher in the GA group. Moreover, on the high-salt diet the frequency of non-dipping hypertension was also significantly higher in GA carriers.
As summarized in Table 4, in patients with the G972R substitution in the IRS-1 gene, an increase in dietary salt intake was associated with a significant risk for insulin resistance and salt-sensitive hypertension. These patients were also at risk for a non-dipper pattern of nocturnal blood pressure decrease. However, after including insulin resistance in this model, the G972R polymorphism was still found to be associated with salt sensitivity $(\mathrm{OR}=1.45,95 \% \mathrm{CI} 1.14-2.56 ; P=0.04)$ but not with non-dipper hypertension $(\mathrm{OR}=0.86,95 \% \mathrm{CI} 0.62-2.14)$. Insulin resistance alone substantially increased the risk for salt-sensitive hypertension $(\mathrm{OR}=3.2$, 95\% CI 1.09-9.28; $P=0.034)$.

In the subgroup of patients with salt-sensitive hypertension, GA carriers had significantly higher HOMA than GG carriers on the

Table 4 The impact of G972R mutation on the risk of insulin resistance, salt-sensitive hypertension and non-dipper hypertension

\begin{tabular}{lccc}
\hline & Odds ratio & $95 \% \mathrm{Cl}$ & $P$ \\
\hline $\begin{array}{l}\text { Insulin resistance } \\
\text { Low-salt diet } \\
\text { High-salt diet }\end{array}$ & 2.47 & $1.33-10.93$ & 0.053 \\
& 11.42 & $7.68-28.44$ & 0.0001 \\
Non-dipper hypertension & & & \\
$\quad$ Low-salt diet & & & \\
$\quad$ High-salt diet & 1.52 & $0.46-4.98$ & 0.484 \\
Salt-sensitive hypertension & 3.60 & $1.07-12.09$ & 0.038 \\
\hline
\end{tabular}

Odds ratio adjusted for age, gender and body mass index.

Table 2 Comparison of biochemical parameters and 24-h blood pressure monitoring on low- and high-salt diet in relation to IRS-1 polymorphism

\begin{tabular}{|c|c|c|c|c|}
\hline & \multicolumn{2}{|c|}{ Low-salt diet } & \multicolumn{2}{|c|}{ High-salt diet } \\
\hline & Gly/Arg patients $(\mathrm{n}=16)$ & Gly/Gly patients $(\mathrm{n}=99)$ & Gly/Arg patients $(\mathrm{n}=16)$ & Gly/Gly patients $(\mathrm{n}=99)$ \\
\hline Glucose (mg dl-1) & $86.81 \pm 7.7$ & $87.32 \pm 8.5$ & $89.11 \pm 6.8$ & $88.20 \pm 7.5$ \\
\hline Insulin $\left(\mu \mid \cup \mathrm{ml}^{-1}\right)$ & $10.82 \pm 4.8$ & $7.01 \pm 3.7^{*}$ & $14.33 \pm 5.4^{\ddagger}$ & $9.17 \pm 4.5^{* *}$ \\
\hline HOMA & $2.22 \pm 0.99$ & $1.53 \pm 0.9 * *$ & $3.11 \pm 1.1^{\ddagger}$ & $1.61 \pm 0.7^{* *}$ \\
\hline Plasma renin activity (ng $\mathrm{Al} \mathrm{ml}{ }^{-1} \mathrm{~h}^{-1}$ ) & $4.78 \pm 1.07$ & $4.50 \pm 0.9$ & $1.73 \pm 0.8^{\ddagger \ddagger}$ & $1.39 \pm 0.6 \pm$ \\
\hline Aldosterone (pg ml-1) & $342.62 \pm 76.9$ & $376.33 \pm 62.1$ & $119.54 \pm 20.5^{\ddagger \ddagger}$ & $112.44 \pm 21.6 \ddagger$ \\
\hline Aldosterone/plasma renin activity ratio & $7.61 \pm 2.3$ & $8.67 \pm 2.2$ & $8.29 \pm 3.4$ & $9.45 \pm 3.3^{\ddagger}$ \\
\hline 24-h urinary sodium excretion (mmol) & $22.61 \pm 3.9$ & $19.11 \pm 4.2$ & $221.12 \pm 8.9$ & $218.42 \pm 9.1$ \\
\hline 24-h mean blood pressure $(\mathrm{mm} \mathrm{Hg})$ & $103.33 \pm 15.0$ & $103.69 \pm 13.5$ & $107.22 \pm 18.6^{\ddagger}$ & $109.17 \pm 17.4$ \\
\hline Daytime blood pressure (mm Hg) & $106.33 \pm 16.0$ & $107.94 \pm 14.5$ & $110.63 \pm 19.8$ & $112.75 \pm 18.7^{\ddagger}$ \\
\hline Nighttime blood pressure (mm Hg) & $94.67 \pm 12.2$ & $94.92 \pm 15.7$ & $100.75 \pm 18.9 \ddagger$ & $101.04 \pm 18.8^{\ddagger}$ \\
\hline Nighttime blood pressure fall $(\mathrm{mm} \mathrm{Hg})$ & $11.67 \pm 5.0$ & $12.98 \pm 5.5$ & $9.88 \pm 4.1^{\ddagger}$ & $11.71 \pm 4.1$ \\
\hline
\end{tabular}

Abbreviations: HOMA, homeostasis model assessment; IRS-1, insulin receptor substrate-1.

${ }^{*} P<0.01,{ }^{*} P<0.005$ in comparison with G972R carriers.

$\ddagger P<0.05, \ddagger \ddagger P<0.001$ in comparison with low-salt diet.

Data are means \pm s.d.

Table 3 Frequency distribution of insulin resistance, non-dipper hypertension and salt-sensitive hypertension

\begin{tabular}{|c|c|c|c|c|c|c|}
\hline & \multicolumn{3}{|c|}{ Gly/Arg carriers $(n=16)$} & \multicolumn{3}{|c|}{ Gly/Gly carriers $(\mathrm{n}=99)$} \\
\hline & High-salt & Normal-salt & Low-salt & High-salt & Normal-salt & Low-salt \\
\hline Insulin resistance $n(\%)$ & $13(81 \%)^{\ddagger \ddagger}$ & $12(75 \%)^{\ddagger \ddagger}$ & $6(37 \%)^{\ddagger}$ & $12(12 \%)$ & $11(11 \%)$ & $11(11 \%)$ \\
\hline Non-dipper hypertension, $n(\%)$ & $12(75 \%)^{\ddagger}$ & $11(68 \%)$ & $5(33 \%)$ & $45(45 \%)$ & $30(30 \%)$ & $23(25 \%)$ \\
\hline Salt-sensitive hypertension, $n(\%)$ & & $14(87 \%)^{\ddagger}$ & & & $56(57 \%)$ & \\
\hline
\end{tabular}

${ }_{\ddagger} P<0.01,{ }^{\ddagger} P<0.001$ in comparison with Gly/Gly carriers receiving the same diet. 
high-salt diet $(3.28 \pm 1.06$ vs. $1.67 \pm 0.7 ; P=0.0007)$ and normal-salt $\operatorname{diet}(3.13 \pm 1.16$ vs. $1.55 \pm 0.78 ; P=0.0086)$. Furthermore, salt-sensitive hypertension substantially increased risk of insulin resistance, but only in the GA group $(\mathrm{OR}=3.47,95 \%$ CI 1.22-9.34; $P=0.017)$. However, the G972R polymorphism was not a marker for the coexistence of both insulin resistance and salt sensitivity $(\mathrm{OR}=1.12$, 95\% CI $0.6-3.8 ; P=0.11$ ).

\section{DISCUSSION}

We found in a sample of 115 patients with mild, never-treated hypertension and without concomitant diabetes mellitus or obesity that the allelic frequency of the G972R polymorphism in the IRS-1 gene was $7 \%$. Earlier studies have shown that the frequency of G972R carriers in healthy subjects ranges from 3 to $10 \%$, and this frequency significantly increases in obese subjects, patients with coronary artery disease, insulin-resistance syndrome and polycystic ovary syndrome, ${ }^{13,14,17,29-31}$ and now, as suggested by this study possibly also in essential hypertension. These observations strongly suggest that, likely by increased insulin resistance, the G972R variant of the IRS-1 gene may contribute to the genetic predisposition to develop cardiovascular disease.

Our results are consistent with this thesis because we found higher fasting insulin levels and higher values of the HOMA index in GA patients in comparison with GG patients. This suggests that the risk conferred by the G972R allele is likely mediated by increases in the serum fasting insulin. A similar underlying mechanism has been suggested in the development of insulin resistance in polycystic ovary syndrome, as Ioannidis et al. demonstrated using the Mandelian randomization approach. ${ }^{31}$ However, some other reports did not confirm these findings. ${ }^{32,33}$ These discrepancies may be related to different amounts of dietary salt intake. Whereas earlier studies did not assess salt intake, we evaluated, for the first time, the impact of different salt loads on insulin resistance in patients with the G972R polymorphism and found that this impact was greatly enhanced on a high-salt diet. This finding seems relevant in patients with arterial hypertension because a high-salt diet was also significantly associated with a risk for developing salt-sensitive hypertension. On the contrary, GG patients on a normal-salt diet had HOMA index values within the normal range. These results suggest that a high-salt diet, in combination with the G972R mutation, may predispose an individual with genetic susceptibility to high salt-induced insulin resistance. This suggestion might be clinically important for all of GA carriers because recent studies have demonstrated that irrespective of age, sex and BMI, subjects with hypertension, ${ }^{34,35}$ or even prehypertension, ${ }^{36}$ have higher rates of conversion to diabetes than those with normal blood pressure. Furthermore, it has been suggested that much of diabetes risk associated with (pre)hypertension may be explained by disorders related to the insulin resistance. ${ }^{36}$

Our results also demonstrate that the G972R polymorphism does not influence the renin-angiotensin-aldosterone system's response to salt load. In both groups of patients, we found a similar increase in PRA and ALDO in response to a low-salt diet, and normal PRA and ALDO inhibition was induced by a high-salt diet.

We also found that the G972R coding variant of IRS-1 was associated with a risk of non-dipper hypertension. No earlier studies have tested for such an association. This phenomenon may be activated by several possible mechanisms. First, non-dipper hypertension may be related to increasing insulin resistance. It has been shown in earlier studies that hyperinsulinemia, insulin resistance and impaired glucose tolerance are common features of non-dippers. ${ }^{37-40}$ Second, the non-dipper pattern of nocturnal blood pressure variation might be associated with the development of salt-sensitive hypertension. ${ }^{41,42}$ It has been well documented that high dietary salt intake impairs several pathways modulating a circadian rhythm of blood pressure, such as an increase in sympathetic activity, ${ }^{43,44}$ hypervolemia, ${ }^{43}$ impaired inhibition of the renin-angiotensin-aldosterone system and impaired renal hemodynamics. ${ }^{44}$ The high-salt diet may also influence nitric oxide production by the endothelial cells, ${ }^{45}$ aggravating the impairment of endothelial function induced by hypertension. ${ }^{19}$ Regardless of the mechanisms involved, the increased frequency of non-dipper hypertension in young G972R carriers with initial stages of hypertension may predict long-term, hypertensioninduced organ complications ${ }^{46,47}$ and increased cardiovascular risk, especially as non-dippers, like those in our study, commonly display an unfavorable lipid profile.

Our data suggest that dietary salt restriction is an important, first-line approach for the non-pharmacological treatment of hypertension in G972R carriers. However, our study has some limitations. First, despite of the fact that we found strong statistical associations between the G972R polymorphism, insulin resistance, abnormal lipid profile, salt sensitivity and non-dipper hypertension, the results of this study should be viewed cautiously given that this is relatively a small cross-sectional study and the sample size was modest. Therefore, further studies testing for such associations on larger populations are needed. Second, the study lacks a control group and thus, statements concerning comparison of allele frequencies in our cohort should be made with caution. Finally, ABPM was performed in a hospital setting, which is obviously different from the everyday conditions of the young subjects studied.

In conclusion, the results of our study suggest that the G972R polymorphism of the IRS-1 gene is associated with insulin resistance, salt sensitivity and non-dipper hypertension.

\section{CONFLICT OF INTEREST}

The authors declare no conflict of interest.

1 Reaven GM. Insulin resistance/compensatory hyperinsulinemia, essential hypertension, and cardiovascular disease. J Clin Endocrinol Metab 2003; 88: 2399-2403.

2 Capaldo B, Lembo G, Napoli R, Rendina V, Albano G, Saccà L, Trimarco B. Skeletal muscle is a primary site of insulin resistance in essential hypertension. Metabolism 1991; 40: 1320-1322.

3 Natali A, Santoro D, Palombo C, Cerri M, Ghione S, Ferrannini E. Impaired insulin action on skeletal muscle metabolism in essential hypertension. Hypertension 1991; 17: $170-178$.

4 Shimamoto K, Hirata A, Fukuoka M, Higashiura K, Miyazaki Y, Shiiki M, Masuda A, Nakagawa $\mathrm{M}$, limura $\mathrm{O}$. Insulin sensitivity and the effects of insulin on renal sodium handling and pressor systems in essential hypertensive patients. Hypertension 1994; 23(suppl.1): I29-I33.

5 Bigazzi R, Bianchi S, Baldari G, Campese VM. Clustering of cardiovascular risk factors in salt-sensitive patients with essential hypertension: role of insulin. Am J Hypertens 1995; 9: 24-32.

6 Harmsen E, Leenen FH. Dietary sodium induced cardiac hypertrophy. Can J Physiol Pharmacol 1992; 70: 580-586.

7 Heimann JC, Drumond S, Alves AT, Barbato AJ, Dichtchekenian V, Marcondes M. Left ventricular hypertrophy is more marked in salt- sensitive than in salt-resistant hypertensive patients. J Cardiovasc Pharmacol 1991; 17(suppl.2): S122-S124.

8 Lind L, Lithell H, Gustafsson IB, Pollare T, Ljunghall S. Metabolic cardiovascular risk factors and sodium sensitivity in hypertensive subjects. Am J Hypertens 1992; 5: 502-505.

9 Allemann $\mathrm{Y}$, Horber FF, Colombo M, Ferrari P, Shaw S, Jaeger P, Weidmann P. Insulin sensitivity and body fat distribution in normotensive offspring of hypertensive parents. Lancet 1993; 341: 327-331.

10 Facchini F, Chen YD, Clinkingbeard C, Jeppesen J, Reaven GM. Insulin resistance, hyperinsulinemia, and dyslipidemia in nonobese individuals with a family history of hypertension. Am J Hypertens 1992; 5: 694-699.

11 Baroni MG, Arca M, Sentinelli F, Buzzetti R, Capici F, Lovari S, Vitale M, Romeo S, Di Mario U. The G972R variant of the insulin receptor substrate-1 (IRS-1) gene, body fat distribution and insulin-resistance. Diabetologia 2001; 44: 367-372. 
12 Baroni MG, Leonetti F, Sentinelli F, Romeo S, Filippi E, Fanelli M, Ribaudo MC, Zappaterreno A, Fallarino M, Di Mario U. The G972R variant of the insulin receptor substrate-1 (IRS-1) gene is associated with insulin resistance in 'uncomplicated' obese subjects evaluated by hyperinsulinemic-euglycemic clamp. J Endocrinol Invest 2004; 27: 754-759.

13 Clausen JO, Hansen T, Bjørbaek C, Echwald SM, Urhammer SA, Rasmussen S, Andersen $\mathrm{CB}$, Hansen L, Almind K, Winther K, Harldsdottir J. Insulin resistance: interactions between obesity and a common variation of insulin receptor substrate- 1 . Lancet 1995; 346: 397-402.

14 Hitman GA, Hawrami K, McCarthy MI, Viswanathan M, Snehalatha C, Ramachandran A, Tuomilehto J, Tuomilehto-Wolf E, Nissinen A, Pedersen O. Insulin receptor substrate-1 gene mutations in NIDDM; implications for the study of polygenic disease. Diabetologia 1995; 38: 481-486.

15 Jellema A, Zeegers MP, Feskens EJ, Dagnelie PC, Mensink RP. Gly972Arg variant in the insulin receptor substrate- 1 gene and association with type 2 diabetes: a meta-analysis of 27 studies. Diabetologia 2003; 46: 990-995.

16 Le Fur S, Le Stunff C, Bougneres P. Increased resistance in obese children who have both 972 IRS-1 and 1057 IRS-2 polymorphisms. Diabetes 2002; 51(Suppl.3): 304-307.

17 Sigal RJ, Doria A, Warram JH, Krolewski AS. Codon 972 polymorphism in the insulin receptor substrate-1 gene, obesity, and risk of non insulin-dependent diabetes mellitus. J Clin Endocrinol Metab 1996; 81: 1657-1659.

18 Burguete-Garcia Al, Cruz-Lopez M, Madrid-Marina V, Lopez-Ridaura R, Hernández-Avila M, Cortina B, Gómez RE, Velasco-Mondragón E. Association of Gly972Arg polymorphism of IRS1 gene with type 2 diabetes mellitus in lean participants of a national health survey in Mexico: a candidate gene study. Metabolism 2010; 59: 38-45.

19 Perticone F, Sciacqua A, Scozzafava A, Ventura G, Laratta E, Pujia A, Federici M, Lauro R, Sesti G. Impaired endothelial function in never-treated hypertensive subjects carrying the Arg ${ }^{972}$ polymorphism in the insulin receptor substrate-1 gene. J Clin Endocrinol Metab 2004; 89: 3606-3609.

20 Baroni MG, D’Andrea MP, Montali A, Pannitteri G, Barillà F, Campagna F, Mazzei E, Lovari S, Seccareccia F, Campa PP, Ricci G, Pozzilli P, Urbinati G, Arca M. A common mutation of the insulin receptor substrate- 1 gene is a risk factor for coronary artery disease. Arterioscler Thromb Vasc Biol 1999; 19: 2975-2980.

21 Mancia G, De Backer G, Dominiczak A, Cifkova R, Fagard R, Germano G, Grassi G, Heagerty AM, Kjeldsen SE, Laurent S, Narkiewicz K, Ruilope L, Rynkiewicz A, Schmieder RE, Boudier HA, Zanchetti A, Vahanian A, Camm J, De Caterina R, Dean V, Dickstein K, Filippatos G, Funck-Brentano C, Hellemans I, Kristensen SD, McGregor K, Sechtem U, Silber S, Tendera M, Widimsky P, Zamorano JL, Erdine S, Kiowski W, Agabiti-Rosei E, Ambrosioni E, Lindholm LH, Viigimaa M, Adamopoulos $S$, Agabiti-Rosei E, Ambrosioni E, Bertomeu V, Clement D, Erdine S, Farsang C, Gaita $D$, Lip G, Mallion JM, Manolis AJ, Nilsson PM, O'Brien E, Ponikowski P, Redon J, Ruschitzka F, Tamargo J, van Zwieten P, Waeber B, Williams B. 2007 Guidelines for the management of arterial hypertension. ESC-ESH task force for the management of arterial hypertension. J Hypertens 2007; 25: 1105-1187.

22 McGowan NJ, Gough K, Padfield PL. Nocturnal dipping is reproducible in the long term. Blood Press Monit 2009; 14: 185-189.

23 Sullivan JM. Salt sensitivity. Definition, conception, methodology, and long-term issues. Hypertension 1991; 17(Suppl.1): I61-168.

24 Bigazzi R, Bianchi S, Baldari D, Sgherri G, Baldari G, Campese VM. Microalbuminuria in salt-sensitive patients. A marker for renal and cardiovascular risk factors. Hypertension 1994; 23: 195-199.

25 Taniguchi A, Nakai Y, Sakai M, Yoshii S, Hayashi M, Nishitani K, Hamanaka D, Nakaishi S, Kamamoto T, Nagata I, Okumura T, Kishimoto H, Fukushima M. Relationship of regional adiposity to insulin resistance in nonobese Japanese type 2 diabetic patients. Diabetes Care 2001; 24: 966-968.

26 Yoshitomi Y, Ishii T, Kaneki M, Tsujibayashi T, Sakurai S, Nagakura C, Miyauchi A. Relationship between insulin resistance and effect of atorvastatin in non-diabetic subjects. J Atheroscler Thromb 2005; 12: 9-13.

27 Mulatero P, Rabbia F, Milan A, Paglieri C, Morello F, Chiandussi L, Veglio F. Drug effects on aldosterone/plasma renin activity ratio in primary aldosteronism. Hypertension 2002; 40: 897-902.
28 Yamada K, Yuan X, Ishiyama S, Shoji S, Kohno S, Koyama K, Koyanagi A, Koyama W, Nonaka K. Codon 972 polymorphism of the insulin receptor substrate-1 gene in impaired glucose tolerance and late-onset NIDDM. Diabetes Care 1998; 21: 753-756.

29 Almind K, Bjørbaek C, Vestergaard H, Hansen T, Echwald S, Pedersen O. Amino acid polymorphism of insulin receptor substrate- 1 in non-insulin-dependent diabetes mellitus. Lancet 1993; 342: 828-832.

30 van Dam RM, Hoebee B, Seidell JC, Schaap MM, Blaak EE, Feskens EJ. The insulin receptor substrate-1 Gly972Arg polymorphism is not associated with type 2 diabetes mellitus in two population-based studies. Diabet Med 2004; 21: 752-758.

31 Ioannidis A, Ikonomi E, Dimou NL, Douma L, Bagos PG. Polymorphisms of the insulin receptor and the insulin receptor substrates genes in polycystic ovary syndrome: a Mendelian randomization meta-analysis. Mol Genet Metab 2010; 99: 174-183.

32 Ito K, Katsuki A, Furuta M, Fujii M, Tsuchihashi K, Hori Y, Yano Y, Sumida Y, Adachi Y. Insulin sensitivity is not affected by mutation of codon 972 of the human IRS-1 gene. Horm Res 1999; 52: 230-234.

33 Koch M, Rett K, Volk A, Maerker E, Haist K, Deninger M, Renn W, Häring HU. Amino acid polymorphism Gly 972 Arg in IRS-1 is not associated to lower clampderived insulin sensitivity in young healthy first degree relatives of patients with type 2 diabetes. Exp Clin Endocrinol Diabetes 1999; 107: 318-322.

34 Weycker D, Nichols GA, O'Keeffe-Rosetti M, Edelsberg J, Vincze G, Khan ZM, Oster G. Excess risk of diabetes in persons with hypertension. J Diabetes Complications 2009; 23: 330-336.

35 Conen D, Ridker PM, Mora S, Buring JE, Glynn RJ. Blood pressure and risk of developing type 2 diabetes mellitus: The Women's Health Study. Eur Heart J 2007; 28: 2937-2943.

36 Mullican DR, Lorenzo C, Haffner SM. Is prehypertension a risk factor for the development of type 2 diabetes? Diabetes Care 2009; 32: 1870-1872.

37 Anan F, Takahashi N, Ooie T, Yufu K, Saikawa T, Yoshimatsu H. Role of insulin resistance in nondipper essential hypertensive patients. Hypertens Res 2003; 26: 669-676.

38 Chen JW, Jen SL, Lee WL, Hsu NW, Lin SJ, Ting CT, Chang MS, Wang PH. Differential glucose tolerance in dipper and nondipper essential hypertension: the implications of circadian blood pressure regulation on glucose tolerance in hypertension. Diabetes Care 1998; $21:$ 1743-1748.

39 Della Mea P, Lupia M, Bandolin V, Guzzon S, Sonino N, Vettor R, Fallo F. Adiponectin, insulin resistance, and left ventricular structure in dipper and nondipper essential hypertensive patients. Am J Hypertens 2005; 18: 30-35.

40 Nakano S, Kitazawa M, Tsuda S, Himeno M, Makiishi H, Nakagawa A, Kigoshi T, Uchida K. Insulin resistance is associated with reduced nocturnal falls of blood pressure in normotensive, nonobese type 2 diabetic subjects. Clin Exp Hypertens 2002; 24: 65-73.

41 Higashi Y, Oshima T, Ozono R, Nakano Y, Matsuura H, Kambe M, Kajiyama G. Nocturnal decline in blood pressure is attenuated by $\mathrm{NaCl}$ loading in salt-sensitive patients with essential hypertension: noninvasive 24-h ambulatory blood pressure monitoring. Hypertension 1997; 30: 163-167.

42 Titze J, Ritz E. Salt and its effect on blood pressure and target organ damage: new pieces in an old puzzle. J Nephrol 2009; 22: 177-189.

43 Just A. Going with the Wnt? Focus on 'Hyperaldosteronism, hypervolemia, and increased blood pressure in mice expressing defective APC'. Am J Physiol Regul Integr Comp Physiol 2009; 297: 571-575.

44 Campese VM, Romoff MS, Levitan D, Saglikes Y, Friedler RM, Massry SG. Abnormal relationship between sodium intake and sympathetic nervous system activity in salt-sensitive patients with essential hypertension. Kidney Int 1982; 21: 371-378.

45 Higashi Y, Oshima T, Watanabe M, Matsuura H, Kajiyama G. Renal response to L-arginine in salt-sensitive patients with essential hypertension. Hypertension 1996; 27: 643-648.

46 Hoshide S, Kario K, Hoshide Y, Umeda Y, Hashimoto T, Kunii O, Ojima T, Shimada K. Associations between nondipping of nocturnal blood pressure decrease and cardiovascular target organ damage in strictly selected community-dwelling normotensives. Am J Hypertens 2003; 16: 434-438.

47 Lurbe E, Redon J, Kesani A, Pascual JM, Tacons J, Alvarez V, Batlle D. Increase in nocturnal blood pressure and progression to microalbuminuria in type 1 diabetes. N Engl J Med 2002; 347: 797-805. 